\title{
Separate and combined effects of cyclic fasting and L-carnitine supplementation in red porgy (Pagrus pagrus, L. 1758)
}

\author{
Natacha Nogueira', Nereida Cordeiro ${ }^{2}$, Paula Canada ${ }^{1}$, Paula Cruz e Silva ${ }^{1}$ \& Rodrigo O A Ozório ${ }^{3}$ \\ ${ }^{1} \mathrm{CMC}$, Centro de Maricultura da Calheta, Direcção Regional de Pescas, Calheta, Portugal \\ ${ }^{2}$ CEM, Centro de Estudos da Macaronésia, Centro de Ciências Exactas e da Engenharia, Universidade da Madeira, Funchal, Portugal \\ ${ }^{3}$ CIMAR/CIIMAR, Centro Interdisciplinar de Investigação Marinha e Ambiental, Universidade do Porto, Porto, Portugal
}

Correspondence: N Nogueira, CMC, Centro de Maricultura da Calheta, Direcção Regional de Pescas, 9370-133 Calheta, Portugal. E-mail: natacha.nogueira@cmcmadeira.org

\begin{abstract}
We examined the effects of cyclic fasting in red porgy (Pagrus pagrus) fed different dietary carnitine levels. Juvenile fish $(23.58 \pm 3.49 \mathrm{~g})$ were divided into eight groups - four groups were fed every day to apparent satiation, while the other four were fasted for 7 days every 2 weeks. In each feeding regime, two replicates were fed an L-carnitine non-supplemented diet $\left(46 \mathrm{mg} \mathrm{kg}^{-1}\right)$ and the other two groups were fed an L-carnitine supplemented diet $\left(630 \mathrm{mg} \mathrm{kg}^{-1}\right)$. Fish fed $630 \mathrm{mg} \mathrm{L-carni-}$ tine accumulated two times more L-carnitine in muscle than fish fed $46 \mathrm{mg}$ L-carnitine. Cyclic fasting reduced the growth performance and lipid content in the liver. Carnitine supplementation did not affect performance and body composition, but decreased the n- 6 PUFA content. Moreover, the combined effects of fasting and carnitine supplementation were observed on reducing the n-3 fatty acid content. Areas of steatosis were found in the livers of red porgy, but the results revealed that supplementation of L-carnitine in cyclic fasted fish contributed towards a lower degree of vacuolization than in fish fed to apparent satiation. Regardless of the feeding regime applied, the spleen of fish fed the L-carnitine-supplemented diet was haemorrhagic and hyper activation of melanomacrophage cells was observed.
\end{abstract}

Keywords: fasting, compensatory growth, carnitine, red porgy

\section{Introduction}

Offshore grow-out systems are inherently dependent on natural conditions to provide a suitable growing environment. The Atlantic coast is prone to violent storms or adverse sea conditions, which limit the accessibility to the site and consequently the ability to deliver feed, subjecting cultured fish to variable periods of fasting. Fish may display a growth spurt when food supplies increase following a period of starvation or restricted feeding, often referred to as catchup or compensatory growth (CG) (Weatherley \& Gill 1981; Ali, Nicieza \& Wootton 2003). Cyclic feeding regimes in fish production attempts to simulate the natural fluctuation in prey availability, triggering CG. Compensatory growth has become a subject of interest in aquaculture, specifically to enhance growth and feed efficiency (Wang, Cui, Yang \& Cal 2000; Foss \& Imsland 2002), potentially reduce production costs and assist in water quality management (Gaylord \& Gatlin 2001). However, feeding practices that utilize CG response to reduce production costs have to consider that the determination of the appropriate feeding frequency is necessary to yield optimal growth and a better survival rate. It is therefore important to consider various regimes and evaluate how much they may influence production. Although a number of studies have observed the cause-effect of cyclic starvation/re-feeding regimes on a variety of physiological responses (Gaylord \& Gatlin 2001; Pérez-Jiménez, Guedes, Morales \& Oliva-Teles 2007), it seems that there is a sequential mobilization of energy reserves. During periods of starvation, fish burn body lipids before protein, with protein being used only when lipid stores are depleted (Weatherley \& Gill 1987). These metabolic adjustments are not just species dependent (Pérez-Jiménez et al. 2007) as they also vary according to age, ontogenetic stage, gender, 
photoperiod season and temperature (Ali, Iqbal, Rana, Athar \& Iqbal 2006). Red porgy is one of the most popular sparid fish species in the Mediterranean region and the Atlantic coast that has been considered to be a good candidate to diversify the aquaculture industry (Divanach, Kentouri, Charalambakis, Pouget \& Sterioti 1993; Kentouri, O'Neil, Divanach \& Charalambakis 1994; Cejas, Fores, Samper, Villamandos \& Jerez 1999). Current research on red porgy nutrition has focused on the basic nutritional requirements of the species (Schuchardt, Vergara, Fernández-Palacios, Kalinowski, Hernández-Cruz, Izquierdo \& Robaina 2007) and in the formulation of specific diets to overcome the discoloration problem of market-sized fish (Kalinowski, Robaina, Fernandez-Palacios, Schuchardt \& Izquierdo 2005; Tejera, Cejas, Rodriguez, Bjerkeng, Jerez, Bolanos \& Lorenzo 2007). So far, little attention has been paid to feeding frequencies. To the best of our knowledge, only Rueda, Martinez, Zamora, Kentouri \& Divanach (1998) have reported on the occurrence of CG in red porgy after 7, 14 or 28 days of food deprivation, followed by satiation feeding for a total duration of 91 days.

Because L-carnitine is a normal constituent of animal tissues and plasma, which is associated with lipid metabolism and has been considered in some cases to be a conditionally essential nutrient, many researchers have looked to investigate the role of dietary carnitine supplementation in growth performance and body composition (Harpaz 2005). The growth-promoting effect of dietary carnitine has generally been explained by an increase in the utilization of dietary energy resulting from increased oxidation of fatty acids (Becker, Schreiber, Angoni \& Blum 1999). Nevertheless, the ability of L-carnitine to increase the growth rate and reduce tissue lipid concentrations has been evaluated in several fish species, with conflicting results. Several studies have investigated the role of L-carnitine supplementation in the Japanese red sea bream, Pagrus major, (Chatzifotis, Takeuchi \& Seikai 1995, 1996; Chatzifotis \& Takeuchi 1997), which closely resembles red porgy. Still, very few data are available on sparids and no data have been published on the possible effects of carnitine supplementation on red porgy growth or body composition.

The aim of the current study is to access the metabolic strategies of red porgy (Pagrus pagrus) to cope with cyclic fasting and subsequent re-feeding and to evaluate the possible influence of dietary carnitine supplementation on this response.

\section{Materials and methods}

\section{Fish and husbandry}

This experiment was conducted at the experimental facilities of Centro de Maricultura da Calheta (CMC), Madeira, Portugal. Fish used in this study were siblings of first-generation broodstock held at the CMC. Before the experiment, red porgies were grown at low densities in $10.000 \mathrm{~L}$ tanks and fed twice daily on a commercial diet for gilthead seabream. Four hundred and eighty juvenile red porgy weighing $23.58 \pm 3.49 \mathrm{~g}$ were randomly distributed in eight cylindro-conical tanks (volume $500 \mathrm{~L}$; water flow $8 \mathrm{~L} \mathrm{~min}^{-1}$ ) supplied with gravel-filtered seawater, under a natural photoperiod (10 L:14 D). Water temperature $\left(21.2 \pm 0.73{ }^{\circ} \mathrm{C}\right)$, salinity $(37 \pm 1.0 \mathrm{ppt})$, $\mathrm{pH}(8.12 \pm 0.09)$ and dissolved oxygen $(6.47 \pm$ $0.64 \mathrm{mg} \mathrm{L}^{-1}$ ) were monitored on a daily basis.

\section{Diets, feeding and design}

The experiment was carried out according to a $2 \times 2$ factorial design, with two replications each. Before the beginning of the experiment, fish were allowed to acclimate to the conditions of the new re-circulation system for 10 days. During this period, fish were fed close to apparent satiation with the non-supplemented carnitine experimental diet $\left(46 \mathrm{mg} \mathrm{kg}^{-1}\right)$. During the feeding trial (64 experimental days), of the eight groups formed (60 individuals each), four groups were fed every day (referred as $\mathrm{C} / 46$ and C/630), while the other four groups were fasted for 7 days every 2 weeks (referred to as S7/Rfl4/46 and S7/Rf14/630). In each feeding frequency, fish were fed either one of two isoproteic $(52 \% \mathrm{CP})$ and isolipidic $(18 \% \mathrm{CL})$ diets containing 46 or $630 \mathrm{mg}$ carnitine $\mathrm{kg}^{-1}$ (Table 1). For the preparation of the diets, dry ingredients were pulverized to about $0.5 \mathrm{~mm}$ particle size in a conventional mill. The ingredients were mixed thoroughly and water was added to obtain $10 \%$ moisture. Thereafter, the mixture was pelleted to $1.0 \mathrm{~mm}$ size and dried overnight at $45^{\circ} \mathrm{C}$, using a convection oven. All diets were stored at $-20{ }^{\circ} \mathrm{C}$ until used. During the feeding trials, all fish were hand fed to apparent satiety twice a day (9:00 and 16:00 hours) and feed intake was recorded on a daily basis.

\section{Sampling and analytical procedures}

During the feeding trial, every 3 weeks $(2$ weeks of feeding +1 week of fasting, for the fasting regime 
Table 1 Formulation and chemical composition of the experimental diets (\%, unless otherwise stated)

\begin{tabular}{|c|c|c|}
\hline \multirow[b]{2}{*}{ Ingredients (\%) } & \multicolumn{2}{|c|}{ Dietary carnitine $\left(\mathrm{mg} \mathrm{kg}^{-1}\right)$} \\
\hline & 46 & 630 \\
\hline Fishmeal (CP 60\%) & 35 & 35 \\
\hline Soyameal concentrate & 20.9 & 20.9 \\
\hline Fish oil & 10.3 & 10.3 \\
\hline Wheat gluten & 12 & 12 \\
\hline Squid hydrolisate & 5 & 5 \\
\hline Dried yeast & 5 & 5 \\
\hline Dried polichaeta & 1 & 1 \\
\hline Wheat & 4.2 & 4 \\
\hline Lecithin & 3 & 3 \\
\hline Bicalcium phosphate & 2.3 & 2.3 \\
\hline Choline & 0.35 & 0.35 \\
\hline Premix* & 1 & 1 \\
\hline Carniking & - & 0.11 \\
\hline \multicolumn{3}{|l|}{ Composition } \\
\hline Dry matter & 91.8 & 91.8 \\
\hline Crude protein & 52 & 52 \\
\hline Crude fat & 18 & 18 \\
\hline Crude ash & 8.8 & 8.8 \\
\hline Phosphorus & 1.5 & 1.5 \\
\hline Carnitine $\left(\mathrm{mg} \mathrm{kg}^{-1}\right)$ & 46 & 630 \\
\hline
\end{tabular}

*Vitamin and mineral supplement (per kg of mixture): vitamins: A, $4000000 \mathrm{IU} ; \mathrm{D}_{3}, 1000000 \mathrm{IU} ; \mathrm{E}, 2.500 \mathrm{mg}$; K, $5000 \mathrm{mg}$; $\mathrm{B}_{12}$, $10 \mathrm{mg} ; \mathrm{B}_{3}, 50000 \mathrm{mg} ; \mathrm{B}_{5}, 25000 \mathrm{mg}$; folic acid, $5000 \mathrm{mg}$; biotin, $500 \mathrm{mg}$; C, $2.500 \mathrm{mg}$; betaine, $250000 \mathrm{mg}$; inositol, $150000 \mathrm{mg}$. Minerals: $\mathrm{Co}, 80 \mathrm{mg}\left(\mathrm{CoSO}_{4}\right) ; \mathrm{Cu}, 1000 \mathrm{mg}\left(\mathrm{CuSO}_{4}\right) ; \mathrm{I}, 120 \mathrm{mg}$ (KI); $\mathrm{Mn}, 4000 \mathrm{mg}\left(\mathrm{MnSO}_{4}\right) ; \mathrm{Zn}, 6000 \mathrm{mg}\left(\mathrm{ZnSO}_{4}\right)$.

$\uparrow 50 \%$ L-carnitine, $35 \%$ silica and $15 \%$ water (Lonza, Basel, Switzerland).

$\mathrm{CP}$, crude protein.

groups), fish were anaesthetized with MS-222, individually measured and weighted. At the end of each sampling period, in a total of three sampling periods, growth performances were determined as weight gain (g), daily growth index (DGI), voluntary feed intake (VFI) and feed conversion ratio (FCR). During the final sampling, the hepatosomatic index (HSI) was also calculated using liver samples from 20 fish per treatment. Seven fish per tank were randomly sampled and pooled for whole body, liver and dorsal muscle composition. Samples were stored at $-80{ }^{\circ} \mathrm{C}$ pending analyses. Before all sampling, fish from each tank were deprived of food for a 24-h period.

\section{Chemical analyses}

Analyses were performed in duplicate following the standard laboratory procedures: tissue samples were freeze-dried (Labconco Freezone 4.5), homogenized before analysis and residual moisture was determined
(Gibertini-Eurotherm dry weight balance) to correct to dry material $(\mathrm{dm})$. Crude lipids of whole body, liver and muscle were extracted using a chloroformmethanol mixture $(1: 2 \mathrm{v} / \mathrm{v})$, according to Bligh and Dyer (1959).

The fatty acid content was determined as FA methyl esters (FAMEs), according to the Lepage and Roy (1986), modified by Cohen, Von Shak and Richmond (1988). In brief, analyses were performed in a gas chromatograph (Agilent HP 6890, Foster city, CA, USA) equipped with a flame ionization detector and a mass selective detector (Agilent 5973). The separation was performed in a polyethylene glycol capillary column (Supercolwax, Sigma-Aldrich/Supelco, Bellefonte, PA, USA) with $30 \mathrm{~m}$ length, $0.25 \mathrm{~mm}$ i.d. and $0.25 \mu \mathrm{m}$ film thickness from Supelco. Fatty acid methyl esters are expressed as mg per $\mathrm{g}$ of $\mathrm{dm}$.

For L-carnitine analyses, five grams of homogenized muscle samples were used for free L-carnitine extraction, following the procedure described by Shimada, Sakuma, Wakamatsu, Fukushima, Sekikawa, Kushida and Mikami (2004).

\section{Histology}

At the end of the experimental study, liver and spleen samples from three fish per tank were collected and fixed in 10\% phosphate-buffered formalin for histological examination. The liver was quickly removed and sliced into pieces and subsequently immersed in $10 \%$ phosphate-buffered formalin. Histological sections of $5 \mu \mathrm{m}$ were stained with Mayer's Haemalum-Putt's eosin, according to Culling (1974). For each fish, sections were examined for general histopathology and the degree of cytoplasm vacuolation of the hepatocytes. The observations were consistently made using a combination of low and high magnification power. For the evaluation of histological changes (nuclear displacement and hepatocellular cytoplasm vacuolization degree), microphotographs were taken using a constant magnification. Circles of $4 \mathrm{~mm}$ diameters were superposed on each picture and cells with steatosis were counted (at least 20 randomly sampled fields were counted per section). Evaluations of liver and spleen microscopic lesions are expressed according to the following semi-quantitative criteria: minimum $(+)$, med$\operatorname{ium}(++)$ and maximum $(+++)$.

\section{Statistical analysis}

The data were analysed as $2 \times 2$ factorial using a general linear model (PROC GLM, SAS 8.02, SAS Insti- 
tute, Cary, NC, USA), which included the effect of feeding frequency (apparent satiation and cyclic fasting) and dietary L-carnitine (46 and $630 \mathrm{mg} \mathrm{kg}^{-1}$ diet) as the main factors and its interactions. Measurements of individual fish in each of two tanks per treatment were used for the statistical analysis of growth performance and chemical body composition analysis Differences between means were reported as significant if $P<0.05$, using Bonferroni's multiple $t$-tests. Normality was tested using the Shapiro-Wilk test. Homogeneity was checked using the absolute residuals according to Levene's test. Non-homogeneous data were arcsine transformed before further statistical analysis.

\section{Results}

\section{Growth}

Throughout the experiment, survival ranged from $95 \%$ to $100 \%$. No disease or clinical infection was observed and fish adapted well to the experimental feed. Table 2 presents the growth performances of red porgy juveniles subjected to the different feeding regimes and experimental diets. Fish grew from an initial $23 \mathrm{~g}$ to a mean final body weight ranging from 44 to $56 \mathrm{~g}$, depending on the dietary treatment. Except for VFI in the last sampling period, there were no differences in the final body weight, DGI or FCR between the fish fed the carnitine-supplemented diet and those fed the basal diet $(P>0.05)$. Conversely, cyclic fasting had a marked effect on growth and feed utilization. At day 21 of the experiment, the weight of red porgy deprived of feed for 1 week was lower than that of fish continuously fed to apparent satiation $(P<0.05)$ (Period 1, Table 2). This tendency continued until the end of the feeding trial (Period 3, Table 2), with weight differences being more pronounced at the end of the trial. While DGI was significantly higher in the unrestricted fed group, VFI showed higher values for the fasted groups $(P<0.05)$ over the entire

Table 2 Growth performance of red porgy juveniles subjected to different feeding regimes (continuously fed; fasting for 7 days/re-feeding for 14 days) and two carnitine levels ( 46 or $630 \mathrm{~g} \mathrm{~kg}^{-1}$ diet) during the three experimental periods

\begin{tabular}{|c|c|c|c|c|c|c|c|}
\hline & \multicolumn{4}{|c|}{ Experimental diets } & \multicolumn{3}{|c|}{$P$ value* } \\
\hline & $C / 46$ & $C / 630$ & S7/Rf14/46 & S7/Rf14/630 & $c$ & $\boldsymbol{F}$ & $C \times F$ \\
\hline \multicolumn{8}{|c|}{ Period 1 (1-21st day) } \\
\hline Initial weight (g) & $23.30 \pm 0.37$ & $22.75 \pm 0.72$ & $24.50 \pm 0.65$ & $23.85 \pm 0.84$ & NS & NS & NS \\
\hline Final weight (g) & $34.29 \pm 0.48$ & $34.27 \pm 1.22$ & $30.48 \pm 3.19$ & $29.17 \pm 1.22$ & NS & 0.006 & NS \\
\hline VFI (\%BW day $\left.{ }^{-1}\right)$ & $2.00 \pm 0.06$ & $1.91 \pm 0.06$ & $2.45 \pm 0.39$ & $2.53 \pm 0.28$ & NS & 0.009 & NS \\
\hline DGI & $1.87 \pm 0.00$ & $1.97 \pm 0.14$ & $1.03 \pm 0.63$ & $0.95 \pm 0.04$ & NS & 0.007 & NS \\
\hline FCR & $1.10 \pm 0.03$ & $1.00 \pm 0.03$ & $1.48 \pm 0.36$ & $1.64 \pm 0.24$ & NS & $<0.001$ & NS \\
\hline \multicolumn{8}{|c|}{ Period 2 (22-42nd day) } \\
\hline Final weight (g) & $46.41 \pm 0.52$ & $46.70 \pm 1.97$ & $38.05 \pm 5.90$ & $36.13 \pm 2.31$ & NS & 0.001 & NS \\
\hline VFI $\left(\% B W\right.$ day $\left.^{-1}\right)$ & $1.38 \pm 0.10$ & $1.41 \pm 0.05$ & $1.83 \pm 0.40$ & $1.94 \pm 0.01$ & NS & $<0.001$ & NS \\
\hline DGI & $1.82 \pm 0.15$ & $1.86 \pm 0.05$ & $1.26 \pm 0.31$ & $1.20 \pm 0.14$ & NS & 0.004 & NS \\
\hline FCR & $0.87 \pm 0.01$ & $0.87 \pm 0.00$ & $1.08 \pm 0.15$ & $1.19 \pm 0.13$ & NS & 0.001 & NS \\
\hline \multicolumn{8}{|c|}{ Period 3 (43-64th day) } \\
\hline Final weight $(\mathrm{g})$ & $56.00 \pm 0.40$ & $56.50 \pm 1.49$ & $43.87 \pm 1.13$ & $42.86 \pm 2.98$ & NS & 0.001 & NS \\
\hline VFI $\left(\% B W\right.$ day $\left.^{-1}\right)$ & $1.08 \pm 0.02$ & $1.20 \pm 0.01$ & $1.26 \pm 0.37$ & $1.42 \pm 0.03$ & 0.001 & $<0.001$ & NS \\
\hline DGI & $1.16 \pm 0.02$ & $1.18 \pm 0.08$ & $0.82 \pm 0.18$ & $0.97 \pm 0.05$ & NS & 0.033 & NS \\
\hline FCR & $1.16 \pm 0.00$ & $1.27 \pm 0.10$ & $1.29 \pm 0.15$ & $1.17 \pm 0.06$ & NS & NS & NS \\
\hline \multicolumn{8}{|l|}{$1-64$ th day } \\
\hline \multicolumn{8}{|c|}{ Period 1-3 (1-64th day) } \\
\hline VFI $\left(\% B W\right.$ day $\left.^{-1}\right)$ & $1.33 \pm 0.03$ & $1.37 \pm 0.02$ & $1.10 \pm 0.01$ & $1.16 \pm 0.06$ & NS & 0.001 & NS \\
\hline DGI & $1.52 \pm 0.04$ & $1.57 \pm 0.06$ & $0.97 \pm 0.05$ & $0.97 \pm 0.07$ & NS & $<0.001$ & NS \\
\hline FCR & $1.03 \pm 0.01$ & $1.03 \pm 0.02$ & $1.25 \pm 0.02$ & $1.31 \pm 0.14$ & NS & 0.009 & NS \\
\hline $\mathrm{HSI}$ & $1.45 \pm 0.10$ & $1.32 \pm 0.05$ & $1.60 \pm 0.90$ & $1.47 \pm 0.08$ & NS & NS & NS \\
\hline
\end{tabular}

*Data are shown as mean $\pm \operatorname{SEM}(n=2)$. Comparisons between groups were made using two-way ANova $(P<0.05)$.

VFI $\left(\% \mathrm{BWday}^{-1}\right)=$ Voluntary feed intake $(100 \times$ crude feed intake $/($ final weight + initial weight $/ 2) /$ day $)$.

DGI $=$ Daily growth index $\left(100 \times\left[(\text { final body weight })^{1 / 3}-(\text { initial body weight })^{1 / 3}\right] \times\right.$ day $\left.^{-1}\right)$.

FCR $=$ Feed conversion ratio (feed consumed/gain).

HSI $(\%)=$ Liver weight/Final body weight $) \times 100(n=20)$.

$C$, effect of carnitine; $F$, effect of fasting; $C \times F$, interaction effect; NS, not significant; VFI, voluntary feed intake; HIS, hepatosomatic index. 
experiment. In the last sampling period, VFI decreased in all the treatments, followed by a reduction in DGI and an increase in FCR. At the end of the experiment, no differences were found in the HSI (\%) among all the groups $(P>0.05)$.

\section{Chemical analysis}

The total carnitine content in the dorsal muscle of all dietary treatments is shown in Fig. 1. During the first 3 weeks (Period 1), the carnitine content was not significantly different regardless of the dietary treatment, but in the second experimental period, fish fed $630 \mathrm{mg} \mathrm{kg}^{-1}$ showed higher L-carnitine contents $(P<0.05)$. Cyclic fasting had no effect on the total carnitine content in the dorsal muscle. Over the same period (Period 2), carnitine supplementation reduced the lipid content in muscle significantly (Fig. 2), and an interaction was observed between carnitine and the feeding regime. Fasted fish fed the carnitine-supplemented diet showed the lowest crude lipid content $(3.86 \%, \mathrm{dm})$. There was no evidence that cyclic fasting alone affected the total lipid content in any of the two periods considered. The effects of feeding regime and L-carnitine level on whole body and liver total lipid content $\left(\mathrm{mg} \mathrm{g}^{-1}, \mathrm{dm}\right)$ and fatty acid composition $\left(\mathrm{mg} \mathrm{g}^{-1}, \mathrm{dm}\right)$ are presented in Table 3 and Table 4. Body lipid content and total FA were similar in all the dietary treatments. The body fatty acid profile was also not significantly different among the treatments, except for 22:5n-3, which reduced in the fasted fish fed the carnitine-supplemented diet $\left(2.28 \pm 1.79 \mathrm{mg} \mathrm{g}^{-1}\right)$. On the other hand, the liver lipid content was significantly lower $(P<0.05)$ in fasted fish than in fish fed continuously to apparent satiation (Table 4). Although no significant differences were observed in the sum of the total fatty acids, several individual fatty acids were significantly affected by the feeding regimes, L-carnitine and their interaction. Carnitine supplementation had a marked effect on the $\Sigma \mathrm{n}-6$ content in the liver, mainly with a reduction in 18:2n-6 and 22:5n-6 fatty acids, as shown in Table 4 . Moreover, the content of selected n-3 fatty acids (18:3n-3, 18:4n-3, 20:4n-3) differed significantly between fish fed the carnitine-supplemented diet and the control diet $(P<0.05)$. Both the carnitine content and the fasting regime affected significantly not only the above-mentioned fatty acids but also docosahexaenoic acid (DHA), eicosopentaenoic acid (EPA), $\Sigma$ n-6 and n-3 highly unsaturated fatty acid (HUFA) contents.

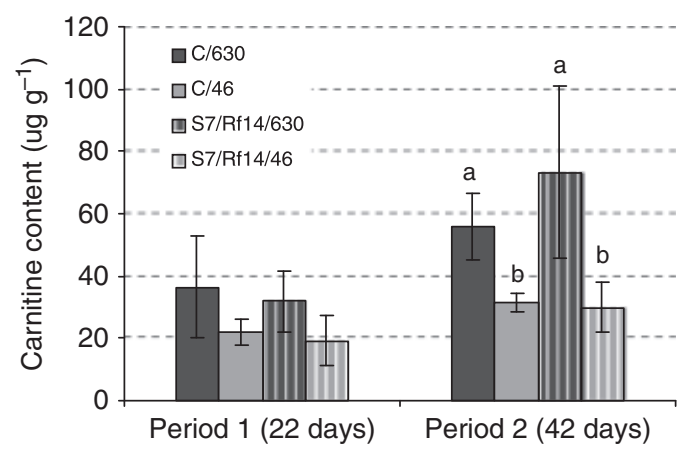

Figure 1 Total carnitine content $\left(\mu \mathrm{gg}^{-1}\right)$ in the muscle of red porgy juveniles after 21 and 42 days of carnitine feeding. Bars represent the standard error of the mean values for each group. Different superscript letters indicate significant differences $(P<0.05)$.

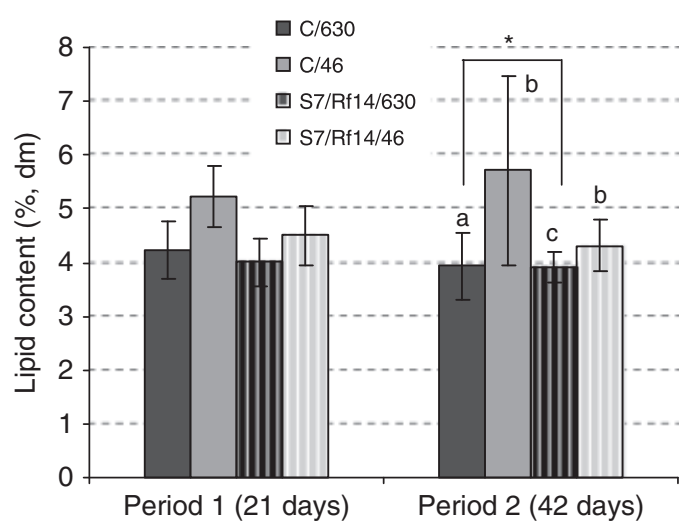

Figure 2 Total lipid content (\%, dm basis) in the muscle of red porgy juveniles after 21 and 42 days of carnitine feeding. Bars represent the standard error of the mean values for each group. Different superscript letters indicate significant differences $(P<0.05)$. * Carnitine $\times$ feeding regime interaction effect $(P<0.05)$.

\section{Histology}

Liver histology of the continuously fed fish (C/46 and $\mathrm{C} / 630$ ) (Fig. $3 \mathrm{a}$ and $\mathrm{b}$ ), as well as of fish exposed to cyclic fasting and fed $46 \mathrm{mg} \mathrm{kg}^{-1}$ carnitine (S7/Rf14/46) (Fig. 3c) showed a moderate lipidic vacuolation of hepatocytes, with areas of steatosis (Table 5). Hepatocytes had lost its shape and little cytoplasmic staining was evident, along with the migration of the hepatocyte nucleus in fish. In contrast, fasted fish fed the L-carnitine-supplemented diet (S7/Rf14/630) (Fig. 3d) displayed a much lower vacuolization degree with a smaller size and hexahedric-like hepatocytes with a large centrally located nucleus and an acidophilic cytoplasm. Haemorrhage and hyper activation 
Table 3 Total crude lipid content ( $\left.\mathrm{mg} \mathrm{g}^{-1}, \mathrm{dm}\right)$ and fatty acid composition $\left(\mathrm{mg} \mathrm{g}^{-1}, \mathrm{dm}\right)$ in whole-body of red porgy juveniles subjected to different feeding regimes (continuously fed; fasting for 7 days/re-feeding for 14 days) and two L-carnitine levels (46 or $630 \mathrm{~g} \mathrm{~kg}^{-1}$ diet) at the end of the study

\begin{tabular}{|c|c|c|c|c|c|c|c|}
\hline & \multicolumn{4}{|c|}{ Experimental diets } & \multicolumn{3}{|c|}{$P$ value $^{1}$} \\
\hline & $C / 46$ & $C / 630$ & S7/Rf14/46 & S7/Rf14/630 & $c$ & $\boldsymbol{F}$ & $C \times F$ \\
\hline Total lipids $\left(\mathrm{mg} \mathrm{g}^{-1}\right)$ & $211.6 \pm 20.6$ & $202.9 \pm 6.5$ & $201.9 \pm 24.0$ & $198.4 \pm 13.0$ & NS & NS & NS \\
\hline \multicolumn{8}{|l|}{ Fatty acids $\left(m g g^{-1}\right)$} \\
\hline $14: 0$ & $6.20 \pm 0.39$ & $7.16 \pm 0.50$ & $6.74 \pm 0.42$ & $6.22 \pm 1.01$ & NS & NS & 0.050 \\
\hline $16: 0$ & $29.37 \pm 1.82$ & $33.12 \pm 1.86$ & $29.94 \pm 1.74$ & $29.71 \pm 4.01$ & NS & NS & NS \\
\hline $18: 0$ & $7.92 \pm 0.32$ & $8.68 \pm 0.35$ & $8.21 \pm 0.59$ & $8.42 \pm 1.19$ & NS & NS & NS \\
\hline $16: 1$ & $10.71 \pm 0.59$ & $12.01 \pm 0.70$ & $11.22 \pm 0.72$ & $10.67 \pm 1.87$ & NS & NS & NS \\
\hline $18: 1 n-9$ & $35.56 \pm 2.17$ & $38.43 \pm 1.57$ & $35.26 \pm 3.59$ & $36.78 \pm 5.52$ & NS & NS & NS \\
\hline $20: 1$ & $8.41 \pm 0.35$ & $9.21 \pm 0.58$ & $8.73 \pm 0.90$ & $9.03 \pm 1.37$ & NS & NS & NS \\
\hline $18: 2 n-6$ & $18.03 \pm 1.37$ & $18.70 \pm 0.73$ & $15.52 \pm 4.46$ & $17.94 \pm 2.37$ & NS & NS & NS \\
\hline $20: 4 n-6$ & $0.23 \pm 0.02$ & $0.24 \pm 0.03$ & $0.22 \pm 0.03$ & $0.23 \pm 0.04$ & NS & NS & NS \\
\hline $22: 5 n-6$ & $0.68 \pm 0.12$ & $0.81 \pm 0.18$ & $0.84 \pm 0.11$ & $0.72 \pm 0.17$ & NS & NS & NS \\
\hline $18: 3 n-3$ & $2.18 \pm 0.65$ & $2.74 \pm 0.17$ & $2.27 \pm 0.496$ & $2.48 \pm 0.46$ & NS & NS & NS \\
\hline $18: 4 n-3$ & $1.79 \pm 0.11$ & $2.00 \pm 0.16$ & $1.88 \pm 0.34$ & $1.67 \pm 0.40$ & NS & NS & NS \\
\hline $20: 4 n-3$ & $1.17 \pm 0.06$ & $1.27 \pm 0.09$ & $1.20 \pm 0.14$ & $1.16 \pm 0.24$ & NS & NS & NS \\
\hline $20: 5 n-3$ & $9.24 \pm 0.47$ & $10.14 \pm 0.97$ & $9.69 \pm 1.32$ & $8.82 \pm 1.91$ & NS & NS & NS \\
\hline $22: 5 n-3$ & $3.18 \pm 0.14$ & $3.72 \pm 0.30$ & $3.37 \pm 1.51$ & $2.28 \pm 1.79$ & 0.003 & NS & NS \\
\hline $22: 6 n-3$ & $24.15 \pm 0.97$ & $26.37 \pm 2.66$ & $26.08 \pm 2.50$ & $24.74 \pm 3.71$ & NS & NS & NS \\
\hline$\Sigma \mathrm{SFA}^{*}$ & $46.61 \pm 2.57$ & $52.51 \pm 2.82$ & $48.68 \pm 2.35$ & $47.68 \pm 6.58$ & NS & NS & NS \\
\hline$\Sigma \mathrm{MUFA} \dagger$ & $62.63 \pm 3.34$ & $68.16 \pm 3.17$ & $63.83 \pm 5.53$ & $65.03 \pm 9.97$ & NS & NS & NS \\
\hline$\Sigma \mathrm{n}-6 \ddagger$ & $20.43 \pm 1.37$ & $21.45 \pm 0.95$ & $18.08 \pm 4.95$ & $20.86 \pm 3.30$ & NS & NS & NS \\
\hline$\Sigma \mathrm{n}-3 \S$ & $43.67 \pm 2.22$ & $48.40 \pm 4.11$ & $46.61 \pm 1.42$ & $43.17 \pm 8.73$ & NS & NS & NS \\
\hline n-3 HUFA & $38.92 \pm 1.64$ & $42.77 \pm 3.72$ & $41.60 \pm 1.16$ & $38.27 \pm 7.76$ & NS & NS & NS \\
\hline C14-18 & $116.66 \pm 7.10$ & $128.30 \pm 6.07$ & $116.13 \pm 10.96$ & $118.80 \pm 17.49$ & NS & NS & NS \\
\hline C20-24 & $57.86 \pm 2.00$ & $63.49 \pm 5.12$ & $62.20 \pm 6.38$ & $59.06 \pm 11.24$ & NS & NS & NS \\
\hline DHA:EPA & $2.61 \pm 0.06$ & $2.60 \pm 0.03$ & $2.69 \pm 0.19$ & $2.84 \pm 0.22$ & NS & 0.023 & NS \\
\hline$\Sigma \mathrm{n}-3 / \Sigma \mathrm{n}-6$ & $2.14 \pm 0.09$ & $2.25 \pm 0.12$ & $2.72 \pm 0.70$ & $2.06 \pm 0.13$ & NS & NS & NS \\
\hline Total & $174.53 \pm 8.84$ & $191.79 \pm 10.09$ & $178.38 \pm 15.24$ & $177.89 \pm 28.42$ & NS & NS & NS \\
\hline
\end{tabular}

Data are shown as mean $\pm \mathrm{SD}(n=2)$. Comparisons between groups were made using two-way ANOVA $(P<0.05)$.

*Includes 12:0, 15:0, 17:0, 19:0, 20:0, 22:0 and 24:0.

$\dagger$ Includes 17:1n-8, 18:1n-7, 20:1n-9, 20:1n-7, 22:1n-11 and 22:1n-9.

$\ddagger$ Includes 18:3n-6, 20:2n-6, 20:3n-6, 22:2n-6 and 22:4n-6.

§Includes 16:3n-3, 16:4n-3 and 20:3n-3.

-Includes 20:5n-3, 22:5n-3 and 22:6n-3.

SFA, saturated fatty acids; MUFA, monounsaturated fatty acids; HUFA, highly unsaturated fatty acids; AA, arachidonic acid, 20:4n-6; EPA, eicopentanoic acid, 20:5n-3; DHA, docosahexaenoic acid, 22:6n-3; $C$, effect of carnitine; $F$, effect of fasting; $C \times F$, interaction effect; NS, not significant.

of melanomacrophage cells were detected in the spleen of fish fed the L-carnitine-supplemented diet.

\section{Discussion}

Compensatory growth is a mechanism by which fish deprived of food make up for the loss in body mass by increasing food consumption and accelerating growth when access to food is restored (Reigh, Williams \& Jacob 2006). The results of this study demonstrated that both groups subjected to the two feeding regimes increased in weight, but the weight gain of fasted fish was lower than the groups fed to apparent satiation. Although fish from the fasted group evidenced a hyperphagic response during the re-feeding protocol (as observed by higher VFI), FCR was generally higher and DGI was lower than continuously fed fish. For comparison, Eroldoğan, Kumlu, Kiris and Sezer (2006), using a similar regime of cyclic fasting, observed partial CG and an improvement in the specific growth rate in $14 \mathrm{~g}$ gilthead seabream. These contradictory results may demonstrate that the CG mechanism is species specific and that the fasting protocol applied was insufficiently long to induce a growth spurt mechanism in $23 \mathrm{~g}$ red porgy juveniles. There is evidence that the frequency of food provision 
Table 4 Total crude lipid content $\left(\mathrm{mg} \mathrm{g}^{-1}, \mathrm{dm}\right)$ and fatty acid composition $\left(\mathrm{mg} \mathrm{g}^{-1}, \mathrm{dm}\right)$ in liver of red porgy juveniles subjected to different feeding regimes (continuously fed; fasting for 7 days/re-feeding for 14 days) and two L-carnitine levels (46 or $630 \mathrm{~g} \mathrm{~kg}^{-1}$ diet) at the end of the study

\begin{tabular}{|c|c|c|c|c|c|c|c|}
\hline & \multicolumn{4}{|c|}{ Experimental diets } & \multicolumn{3}{|l|}{$P$ value $^{1}$} \\
\hline & $C / 46$ & $C / 630$ & S7/Rf14/46 & S7/Rf14/630 & C & $\mathbf{F}$ & $\mathbf{C} \times \mathbf{F}$ \\
\hline Total lipids $\left(\mathrm{mg} \mathrm{g}^{-1}\right)$ & $292.0 \pm 16.9$ & $234.3 \pm 44.2$ & $212.3 \pm 8.2$ & $219.7 \pm 42.2$ & NS & 0.036 & NS \\
\hline \multicolumn{8}{|l|}{ Fatty acids $\left(m g g^{-1}\right)$} \\
\hline 14:0 & $12.50 \pm 0.88$ & $11.78 \pm 3.03$ & $12.07 \pm 0.08$ & $10.16 \pm 3.08$ & NS & NS & NS \\
\hline $16: 0$ & $47.98 \pm 2.29$ & $44.88 \pm 11.62$ & $46.85 \pm 0.52$ & $40.82 \pm 10.08$ & NS & NS & NS \\
\hline 18:0 & $12.01 \pm 0.88$ & $11.04 \pm 2.36$ & $12.14 \pm 0.08$ & $10.57 \pm 2.27$ & NS & NS & NS \\
\hline $16: 1$ & $21.57 \pm 1.08$ & $20.77 \pm 5.09$ & $21.95 \pm 0.01$ & $18.27 \pm 5.35$ & NS & NS & NS \\
\hline $18: 1 n-9$ & $50.49 \pm 4.09$ & $44.71 \pm 10.76$ & $48.52 \pm 0.18$ & $40.14 \pm 12.00$ & NS & NS & NS \\
\hline $20: 1$ & $11.58 \pm 1.42$ & $9.93 \pm 1.60$ & $10.66 \pm 0.05$ & $8.67 \pm 2.62$ & NS & NS & NS \\
\hline $18: 2 n-6$ & $17.01 \pm 1.13$ & $15.18 \pm 2.09$ & $19.25 \pm 0.00$ & $13.73 \pm 3.85$ & 0.035 & NS & NS \\
\hline $20: 4 n-6$ & $0.05 \pm 0.06$ & $0.00 \pm 0.00$ & $0.18 \pm 0.02$ & $0.00 \pm 0.00$ & NS & NS & NS \\
\hline $22: 5 n-6$ & $0.18 \pm 0.06$ & $0.12 \pm 0.02$ & $0.22 \pm 0.00$ & $0.14 \pm 0.00$ & $<0.001$ & NS & NS \\
\hline $18: 3 n-3$ & $1.03 \pm 0.17$ & $0.94 \pm 0.08$ & $1.46 \pm 0.01$ & $0.89 \pm 0.21$ & 0.009 & NS & 0.023 \\
\hline $18: 4 n-3$ & $0.30 \pm 0.08$ & $0.30 \pm 0.02$ & $0.48 \pm 0.01$ & $0.28 \pm 0.05$ & 0.024 & NS & 0.006 \\
\hline $20: 4 n-3$ & $0.29 \pm 0.07$ & $0.30 \pm 0.03$ & $0.55 \pm 0.01$ & $0.31 \pm 0.06$ & 0.007 & 0.003 & 0.001 \\
\hline $20: 5 n-3$ & $1.81 \pm 0.39$ & $2.05 \pm 0.08$ & $2.89 \pm 0.05$ & $1.91 \pm 0.23$ & NS & 0.054 & 0.001 \\
\hline $22: 5 n-3$ & $0.69 \pm 0.15$ & $0.88 \pm 0.04$ & $1.22 \pm 0.04$ & $0.71 \pm 0.13$ & NS & NS & $<0.001$ \\
\hline $22: 6 n-3$ & $8.10 \pm 0.89$ & $9.52 \pm 0.99$ & $10.31 \pm 0.22$ & $7.67 \pm 0.59$ & NS & NS & 0.001 \\
\hline$\Sigma \mathrm{SFA}^{*}$ & $77.20 \pm 3.56$ & $71.97 \pm 17.79$ & $75.77 \pm 0.74$ & $65.46 \pm 16.36$ & NS & NS & NS \\
\hline$\Sigma$ MUFA $\dagger$ & $95.14 \pm 7.27$ & $85.21 \pm 17.92$ & $91.40 \pm 0.01$ & $75.31 \pm 22.50$ & NS & NS & NS \\
\hline$\Sigma n-6 \ddagger$ & $17.81 \pm 2.02$ & $15.75 \pm 1.13$ & $20.65 \pm 0.01$ & $14.49 \pm 3.88$ & 0.029 & NS & NS \\
\hline$\Sigma \mathrm{n}-3 \S$ & $13.02 \pm 0.87$ & $14.72 \pm 1.78$ & $18.19 \pm 0.34$ & $12.72 \pm 1.27$ & NS & NS & 0.001 \\
\hline n-3 HUFA & $8.62 \pm 0.94$ & $9.88 \pm 0.91$ & $11.26 \pm 0.24$ & $8.12 \pm 0.64$ & NS & NS & 0.001 \\
\hline C14-18 & $168.44 \pm 7.39$ & $154.60 \pm 35.62$ & $169.13 \pm 0.92$ & $139.81 \pm 37.87$ & NS & NS & NS \\
\hline C20-24 & $35.45 \pm 2.27$ & $33.71 \pm 3.06$ & $37.82 \pm 0.48$ & $28.81 \pm 6.21$ & NS & NS & NS \\
\hline DHA:EPA & $4.58 \pm 0.73$ & $4.59 \pm 0.41$ & $3.57 \pm 0.01$ & $4.03 \pm 0.22$ & NS & 0.019 & NS \\
\hline$\Sigma n-3 / \Sigma n-6$ & $0.73 \pm 0.09$ & $0.94 \pm 0.07$ & $0.88 \pm 0.02$ & $0.91 \pm 0.16$ & NS & NS & NS \\
\hline Total & $203.90 \pm 8.71$ & $188.31 \pm 38.20$ & $206.95 \pm 0.44$ & $168.62 \pm 44.06$ & NS & NS & NS \\
\hline
\end{tabular}

Data are shown as mean $\pm \mathrm{SD}(n=2)$. Comparisons between groups were made using two-way ANova $(P<0.05)$.

*Includes 12:0, 15:0, 17:0, 19:0, 20:0, 22:0 and 24:0.

$\dagger$ Includes 17:1n-8, 18:1n-7, 20:1n-9, 20:1n-7, 22:1n-11 and 22:1n-9.

$\ddagger$ Includes 18:3n-6, 20:2n-6, 20:3n-6, 22:2n-6 and 22:4n-6.

§Includes 16:3n-3, 16:4n-3 and 20:3n-3.

-Includes 20:5n-3, 22:5n-3 and 22:6n-3.

SFA, saturated fatty acids; MUFA, monounsaturated fatty acids; HUFA, highly unsaturated fatty acids; AA, arachidonic acid, 20:4n-6; EPA, eicopentanoic acid, 20:5n-3; DHA, docosahexaenoic acid, 22:6n-3; $C$, effect of carnitine; $F$, effect of fasting; $C \times F$, interaction effect; NS, not significant.

(or conversely, the frequency and duration of food shortage) can be decisive on fish growth (Ali et al. 2003; Eroldoğan, Kumlu \& Sezer 2006). Although Rueda et al. (1998) demonstrated that $190 \mathrm{~g}$ red porgies showed full CG on re-feeding following fasting, the authors also concluded that fish showed $4 \%$ weight loss after fasting for 7 days when compared with a continuously fed group. Still, by the end of the experiment, the authors found HSI values that were similar to those of the continuously fed controls. Similarly, in our study, no significant differences were observed for the HSI, indicating the importance of the liver during short periods of food deprivation (Collins \& Anderson 1995; Rueda et al. 1998).
In both feeding regimes, the diet with $630 \mathrm{mg} \mathrm{kg}^{-1}$ carnitine did not improve either the growth performance or feed utilization in red porgy. Nevertheless, fish fed the carnitine-supplemented diet tended to eat more than those fed the non-supplemented diet, although the values were not significantly different. Nonetheless, 2 months after feeding, despite no visible effect in promoting growth, muscle carnitine was significantly higher in fish fed $630 \mathrm{mg} \mathrm{kg}^{-1}$ diet. In agreement with our results, several studies also reported no beneficial growth effects of carnitine supplementation in hybrid sea bass (Gaylord \& Gatlin 2000), European sea bass (Dias, Arzel, Corraze \& Kaushik 2001) or African catfish (Ozório, Verreth, Aragão, 

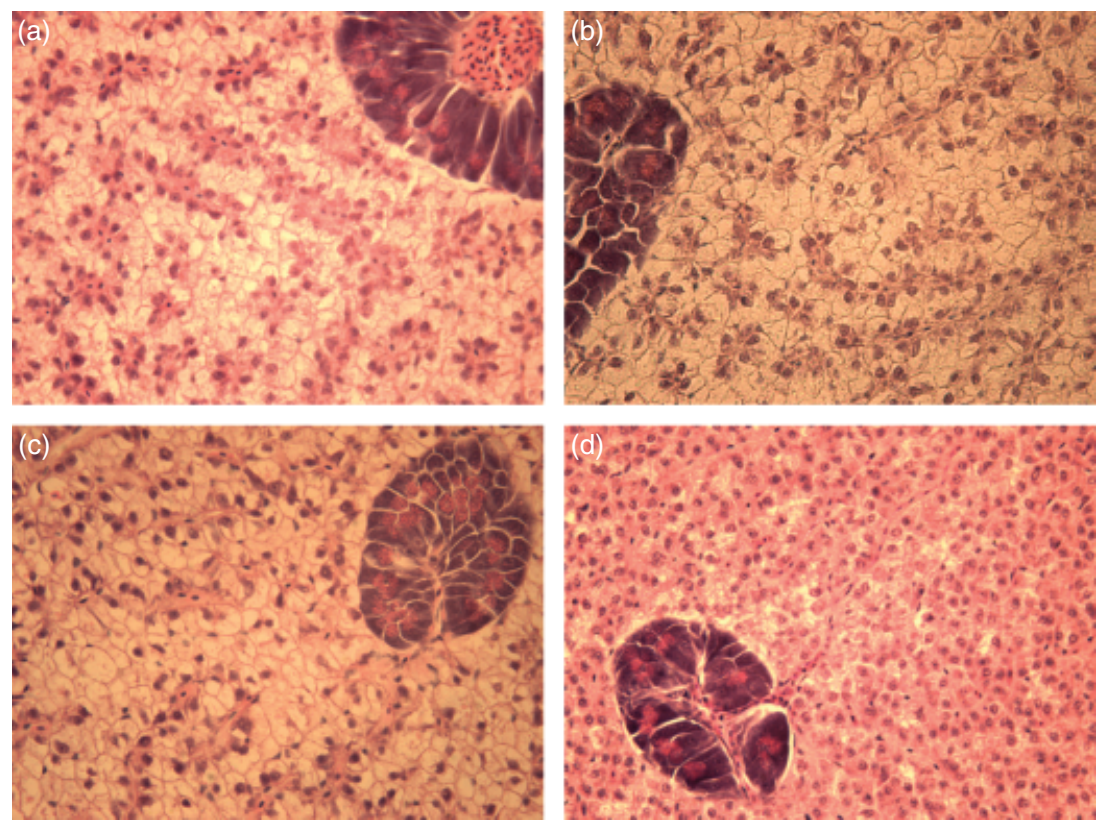

Figure 3 Livers of red porgy subjected to two feeding regimes and L-carnitine levels. $\times 273$ (a) Continuously fed fish with $46 \mathrm{mg} \mathrm{kg}^{-1}$ carnitine supplementation (C/46). Hepatocytes with migration of nuclei and moderately increased cytoplasm vacuolization. (b) Continuously fed fish with $630 \mathrm{mg} \mathrm{kg}^{-1}$ carnitine supplementation (C/630). Hepatocytes with migration of nuclei and moderately increased cytoplasm vacuolization. (c) Fasted fish fed $46 \mathrm{mg} \mathrm{kg}^{-1}$ carnitine supplementation (S7/Rf14/46). Hepatocytes with migration of nuclei and severe lipid vacuole accumulation. (d) Fasted fish fed $630 \mathrm{mg} \mathrm{kg}^{-1}$ carnitine supplementation (S7/Rf14/630). Hepatocytes with large centrally located nuclei and an acidophile cytoplasm.

Table 5 Evaluation of liver and spleen microscopic lesions* of red porgy juveniles subjected to different feeding regimes (continuously fed; fasting for 7 days/re-feeding for 14 days) and L-carnitine levels (46 or $630 \mathrm{~g} \mathrm{~kg}^{-1}$ diet)

\begin{tabular}{|c|c|c|c|c|}
\hline & Cl46 & $C / 630$ & S7/Rf14/46 & S7/Rf14/630 \\
\hline \multicolumn{5}{|l|}{ Liver } \\
\hline Hypertrophy/cellular steatosis of the hepatocyte & +++ & +++ & +++ & ++ \\
\hline Congestion of blood vessels & +++ & ++ & + & + \\
\hline Focal haemorrhage into the liver & ++ & +++ & + & +++ \\
\hline \multicolumn{5}{|l|}{ Spleen } \\
\hline Lysed melanomacrophages and necrosis of acinar cells & + & +++ & ++ & +++ \\
\hline Intense haemorrhage & ++ & +++ & ++ & ++ \\
\hline
\end{tabular}

*Expressed as minimum $(+)$, medium $(++)$ and maximum $(+++)$.

Vermeulen, Schrama, Verstegen \& Huisman 2003). By contrast, improved growth effects using $600 \mathrm{mg} \mathrm{kg}^{-1}$ carnitine were observed in beluga sturgeon juveniles (Mohseni, Ozório, Pourkazemi \& Bai 2008) and rohu juveniles fed up to $500 \mathrm{mg} \mathrm{kg}^{-1}$ carnitine (Keshavanath \& Renuka 1998). These wide variations in the result suggest that the effectiveness of dietary carnitine supplementation may be influenced by multiple interacting factors, such as diet composition, species differences or biochemical, metabolic and physiological activities, as in the case of distinct developmental stages of fish (Harpaz 2005; Ozório 2009). The lipid content in muscle was significantly reduced in fish fed a high-carnitine diet, and an interaction was observed between the diet and the feeding regime. The above observations concur with an earlier study of Santulli and D'Amelio (1986), and recently, Ma, Xu, Shao, Xu, Hung, Hu and Zhuo (2008), who reported that carnitine reduced the muscle lipid content in seabass and black sea bream respectively. Under regular 
feeding regimes, fish grow and store energy reserves, while metabolic processes in fasted fish are performed by mobilizing body nutrient stores, leading to alterations in the muscle composition (Power, Melo \& Santos 2000). It is predictable that during a fasting period, carnitine may increase the catabolism of body lipid, sparing body protein for anabolic processes (Brass \& Hoppel 1978; Miyasaki, Sato, Yoshinaka \& Sakaguchi 1995).

With very few exceptions, neither the whole body lipid content nor the total fatty acids were significantly affected by L-carnitine supplementation or the feeding regime. The reports on the effects of dietary L-carnitine on the proximate compositions are inconsistent. In accordance with our findings, the absence of a lipotropic action of carnitine supplementation on the whole body lipid content has been reported for rainbow trout (Rodehutscord 1995), hybrid tilapia (Becker et al. 1999; Du, Liu, Tian, Liu, Feng \& Liang 2002; Yang, Wen, Liou \& Liu 2009), European sea bass (Dias et al. 2001) and black seabream (Ma et al. 2008). The lack of changes in the total body lipid content could be explained by the fact that energy reserves in the liver were used to satisfy the demands during starvation. In the current study, fasted fish had a lower liver lipid content than the continuously fed group, which is consistent with what Webster,Tidwell, Goodgame and Yancey (2007) found in Channel catfish. Commonly, fish undergoing a period of starvation satisfy the energy requirements by utilizing lipid stores (Weatherley \& Gill 1987). Because the liver is the first storage site where lipid and glycogen are depleted in fish (Ozório, Van Ginneken, Bessa, Verstegen, Verreth \& Huisman 2010), we expected to observe a relationship between fasting and liver lipid content.

It is known that the selective use of fatty acids for energy in fish tissues will preserve PUFA and HUFA in preference to other fatty acids (Egginton 1996). Several studies have reported decreased levels of saturated and monounsaturated fatty acids (SFA and MUFA) contents in response to fasting, whereas PUFA levels had a tendency to remain relatively constant (Dave, Johansson-Sjobeck, Larsson, Lewander \& Lidman 1976; Ota, Takagi \& Kosaka 1980). In the present study, SFA and MUFA were not significantly affected by the dietary treatments applied, although a reduction is observed in fish fed the carnitinesupplemented diet. Moreover, analysis of the fatty acid profile in the liver revealed that fasting had a marked effect in reducing the $\mathrm{n}-3$ fatty acids and the n-3 HUFA, but only when interacting with dietary carnitine supplementation. Dietary carnitine supplements, in combination with stress factors, such as exercise, are known to enhance the oxidation of longchain fatty acids, decreasing their deposition in body tissues (Ozório et al. 2010). In our study, carnitine supplementation, regardless of the feeding regime, contributed towards a reduction in the $n-6$ fatty acids group as well as linolenic acid (18:3n-3), while the DHA (22:6n-3) and EPA (20:5n-3) values were not affected. This is consistent with earlier studies on red sea bream, where EPA, DHA, n-3 and n-6 fatty acids in the liver were reduced in red seabream fed carnitine- and lysine-supplemented diets (Chatzifotis et al. 1996). Similarly, Ozório et al. (2010), working with African catfish, also found that the supplementation of L-carnitine contributed towards the disappearance of n-3 and n- 6 fatty acids. In agreement with the changes in the liver fatty acid content, histological results also showed a carnitine supplementation effect in both feeding regimes, contributing towards a decrease in the cytoplasmatic vacuolation of the hepatocytes and a lower nuclear displacement. Steatosis is a sign that dietary lipid levels have exceeded the capacity of the hepatic cell to oxidize fatty acids and that large amounts of triacylglycerols are being synthesized and deposited in vacuoles (Caballero, Izquierdo, Kjrsvik, Fernández \& Rosenlund 2004; Wassef,Wahby \& Sakr 2007). Caballero et al. (2004), when testing the inclusion of vegetable oils in sea bream diets, were able to establish an order between the characteristic fatty acids of vegetable oils and the appearance of steatosis: linoleic acid (18:2n-6) $>$ linolenic acid (18:3n-3) > oleic acid (18:1n-9). In the current study, fasted fish fed a diet supplemented with dietary L-carnitine showed the lowest values of linoleic and linolenic acid, suggesting that the recovery of liver morphology might be associated with the utilization of these fatty acids. Melanomacrophage serve as repositories for end-products of cell breakdown, and there have been reports on increased deposition in the spleen and kidney promoted by starvation (Agius \& Roberts 1980; Micale \& Perdichizzi 1990). In our study, regardless of the feeding regime, an increased lysis of the melanomacrophages and necrosis of the acinar cells were observed in the spleen of fish fed carnitine-supplemented diet. These results may be correlated to an accelerated catabolic tissue breakdown induced by carnitine supplementation.

In conclusion, the feeding regime adopted suggests a poor ability of red porgy to achieve the same weight as their unrestricted fed counterparts. A longer fast and re-feeding period should be further investigated in order to induce the growth spurt mechanism. The liver lipid content decreased with cyclic fasting, 
whereas the body lipid content remained unaltered, regardless of the dietary treatments. The fatty acid profile in the liver was affected by the interaction between carnitine supplementation and feeding regime, which may have contributed towards the recovery of the normal morphology of red porgies' livers. Under our experimental conditions, L-carnitine supplementation had no effect on growth, but clearly affected the L-carnitine and lipid content in the muscle.

\section{Acknowledgments}

The authors would like to thank the staff of CMC for providing excellent technical conditions for our experiment. Thanks are due to Prof. José Prates (School of Veterinary Medicine, Lisbon) for carrying out the carnitine analyses reported here. The Portuguese Foundation for Science and Technology sponsored this work through the Research Centre of Macaronesia Studies.

\section{References}

Agius C. \& Roberts R.J. (1980) Effects of starvation on the melano-macrophage centres of fish. Journal of Fish Biology 19, 161-169.

Ali M., Nicieza A. \& Wootton R.J. (2003) Compensatory growth in fishes: a response to growth depression. Fish and Fisheries 4, 147-190.

Ali M., Iqbal R., Rana S.A., Athar M. \& Iqbal F. (2006) Effect of feed cycling on specific growth rate, condition factor and RNA/DNA ratio of Labeo rohita. AfricanJournal of Biotechnology 5(17), 1551-1556.

Becker K., Schreiber S., Angoni C. \& Blum R. (1999) Growth performance and feed utilization response of Oreochromis niloticus $\times$ Oreochromis aureus hybrids to L-carnitine measured over a full fattening cycle under commercial conditions. Aquaculture 174, 313-322.

Bligh E.G. \& Dyer W.J. (1959) A rapid method of total lipid extraction and purification. CanadianJournal of Biochemistry and Physiology 37, 911-917.

Brass E.P. \& Hoppel C.L. (1978) Carnitine metabolism in the fasting rat. Journal of Biological Chemistry 253, 2268826993.

Caballero M.J., Izquierdo M.S., Kjrsvik E., Fernández A.J. \& Rosenlund G. (2004) Histological alterations in the liver of sea bream, Sparus aurata L., caused by short- or longterm feeding with vegetable oils. Recovery of normal morphology after feeding fish oil as the sole lipid source. Journal of Fish Diseases 27, 531-541.

Cejas J.R., Fores R., Samper M., Villamandos J.E., Jerez S. (1999) Resultados preliminares de engorde del bocinegro $(P$. pagrus). In: Actas del VII Congreso Nacional de Acuicultura,
19-21. Mayo 1999, Las Palmas de Gran Canaria, Espana, (ed. by Viceconsejeria de Agricultura y Pesca, Gobierno de Canarias), pp. 83-83. Viceconsejeria de Agricultura y Pesca.

Chatzifotis S. \& Takeuchi T. (1997) Effect of supplemental carnitine on body weight loss, proximate and lipid compositions and carnitine content of Red Sea bream (Pagrus major) during starvation. Aquaculture 158, 129-140.

Chatzifotis S.,Takeuchi T. \& Seikai T. (1995) The effect of dietary L-carnitine on growth performance and lipid composition in red sea bream fingerlings. Fisheries Science 61, 1004-1008.

Chatzifotis S.,Takeuchi T. \& Seikai T. (1996) The effect of dietary carnitine supplementation on growth of red sea bream (Pagrus major) fingerlings at two levels of dietary lysine. Aquaculture 147, 235-248.

Cohen Z., Von Shak A. \& Richmond A. (1988) Effect of environmental conditions on fatty acid composition of the red algae Porphyridium cruentum: correlation to growth rate. Journal of Phycology 24, 328-332.

Collins A.L. \& Anderson T.A. (1995) The regulation of endogenous energy stores during starvation and refeeding in the somatic tissues of the golden perch. Journal of Fish Biology 47, 1004-1015.

Culling C.F.A. (1974) Handbook of Histological and Histochemical Techinques, 3rd edn. Butterworth \& G.O. Publishers, London, 712pp.

Dave G., Johansson-Sjobeck M.L., Larsson A., Lewander K. \& Lidman U. (1976) Metabolic and haematological effects of starvation in the European eel, Anguilla anguilla L. III. Fatty acid composition. Comparative Biochemistry and Physiology 53B, 509-515.

Dias J., Arzel J., Corraze G. \& Kaushik S.J. (2001) Effects of dietary L-carnitine supplementation on growth and lipid metabolism in European seabass (Dicentrarchus labrax). Aquaculture Research 32, 206-215.

Divanach P., Kentouri M., Charalambakis G., Pouget F. \& Sterioti A. (1993) Comparison of growth performance of six Mediterranean fish species reared under intensive farming conditions in Crete (Greece), in raceways with the use of self feeders. In: Production, Environment and Quality, Bordeaux Aquaculture ?92. Ghent, Belgium, (ed. by G. Barnabe \& P. Kestemont), pp. 285-297. European Aquaculture Society, Special Publication No. 18.

Du Z.Y., Liu Y.J.,Tian L.X., Liu D.H., Feng J. \& Liang G.Y. (2002) Effects of two different carnitine isomers on growth and body composition of hybrid Oreochromis miloticus i $\times$ Oreochromis aureus 0 . Journal of Fisheries of China 26, 259-264 (in Chinese with English abstract).

Egginton S. (1996) Effect of temperature on optimal substrate for B-oxidation. Journal of Fish Biology 49, 753-758.

Eroldoğan O.T., Kumlu M., Kiris G.A. \& Sezer B. (2006) Compensatory growth response of Sparus aurata following different starvation and refeeding protocols. Aquaculture Nutrition 12, 203-210. 
Eroldoğan O.T., Kumlu M. \& Sezer B. (2006) Effects of starvation and re-alimentation periods on growth performance and hyperphagic response of Sparus aurata. Aquaculture Research 37, 535-537.

Foss A. \& Imsland A.K. (2002) Compensatory growth in the spotted wolfish Anarhichas minor (Olafsen) after a period of limited oxygen supply. Aquaculture Research 33, 1097-1101.

Gaylord T.G. \& Gatlin D.M. (2000) Dietary lipid level but not L-carnitine affects growth performance of hybrid striped bass (Morone chrysops $\times$ Morone saxatilis). Aquaculture 190, 237-246.

Gaylord T.G. \& Gatlin D.M. (2001) Dietary protein and energy modifications to maximize compensatory growth of channel catfish (Ictalurus punctatus). Aquaculture 194, 337-348.

Harpaz S. (2005) L-carnitine and its attributed functions in fish culture and nutrition - a review. Aquaculture 249, 3-21.

Kalinowski C.T., Robaina L.E., Fernandez-Palacios H., Schuchardt D. \& Izquierdo M.S. (2005) Effect of different carotenoid sources and their dietary levels on red porgy (Pagrus pagrus) growth and skin colour. Aquaculture 244, 223-231.

Kentouri M., O'Neil D., Divanach P. \& Charalambakis G. (1994) A study of the quantitative water requirement of red porgies Pagrus pagrus L. Pisces: Sparidae during early on growing under self feeding conditions. Aquaculture $\mathbf{2 5}$, 741-752.

Keshavanath P. \& Renuka P. (1998) Effect of dietary L-carnitine on growth and body composition of fingerling rohu, Labeo rohita (Hamilton). Aquaculture Nutrition 4, 83-87.

Lepage G. \& Roy C.C. (1986) Direct transesterification of all classes of lipids in one-step reaction. Journal of Lipid Research 27, 114-119.

Ma J.J., Xu Z.R., Shao Q.J., Xu J.Z., Hung S.S.O., Hu W.L. \& Zhuo L.Y. (2008) Effect of dietary supplemental L-carnitine on growth performance, body composition and antioxidant status in juvenile black sea bream, Sparus macrocephalus. Aquaculture Nutrition 14, 464-471.

Micale V. \& Perdichizzi F. (1990) A quantitative and histochemical study on melano-macrophage centres in the spleen of the teleost fish Diplodus annularis L. Journal of Fish Biology 37, 191-197.

Miyasaki T., Sato M., Yoshinaka R. \& Sakaguchi M. (1995) Effect of vitamin $\mathrm{C}$ on lipid and carnitine metabolism in rainbow trout. Fisheries Science 61, 501-506.

Mohseni M., Ozório R.O.A., Pourkazemi M. \& Bai S.C. (2008) Effects of dietary L-carnitine supplements on growth and body composition in beluga sturgeon (Huso huso) juveniles. Journal of Applied Ichthyology 24, 646-649.

Ota T., Takagi T. \& Kosaka S. (1980) Changes in lipids of young and adult saury, Cololabis saira (Pisces). Marine Ecology Progress Series 3, 11-17.

Ozório R.O.A. (2009) Dietary L-carnitine supplementation to cultivated fish: a mini-review. Current Nutrition \& Food Science 5, 40-48.

Ozório R.O.A., Verreth J.A.J., Aragão C.R., Vermeulen C.J., Schrama J.W., Verstegen M.W.A. \& Huisman E.A. (2003)
Dietary carnitine supplements increased lipid metabolism and decreased protein oxidation in African catfish (Clarias gariepinus) juveniles fed high fat levels. Journal of Aquaculture in the Tropics 18(3), 225-238.

Ozório R.O.A., Van Ginneken V.J.T., Bessa R.J.B., Verstegen M.W.A., Verreth J.A.J. \& Huisman E.A. (2010) Effect of exercise on L-carnitine and lipid metabolism in African catfish (Clarias gariepinus) fed different dietary L-carnitine and lipid levels. British Journal of Nutrition 103, 1139-1150.

Pérez-Jiménez A., Guedes M.J., Morales A.E. \& Oliva-Teles A. (2007) Metabolic responses to short starvation and refeeding in Dicentrarchus labrax. Effect of dietary composition. Aquaculture 265, 325-335.

Power D.M., Melo J. \& Santos C.R.A. (2000) The effect of food deprivation and refeeding on the liver, thyroid hormones and transthyretin in sea bream. Journal of Fish Biology $\mathbf{5 6}$, 374-387.

Reigh R.C., Williams M.B. \& Jacob B.J. (2006) Influence of repetitive periods of fasting and satiation feeding on growth and production characteristics of channel catfish, Ictalurus punctatus. Aquaculture 254, 506-516.

Rodehutscord M. (1995) Effects of supplemental dietary L-carnitine on the growth and body composition of rainbow trout (Oncorhynchus mykiss) fed high-fat diets. Journal of Animal Physiology and Animal Nutrition 73, 276-279.

Rueda F.M., Martinez F.J., Zamora S., Kentouri M. \& Divanach P. (1998) Effect of fasting and refeeding on growth and body composition of red porgy, Pagrus pagrus L. Aquaculture Research 29, 447-452.

Santulli A. \& D'Amelio V. (1986) Effects of supplemental dietary carnitine on the growth and lipid metabolism of hatchery reared sea bass (Dicentrarchus labrax L.). Aquaculture 59, 177-186.

Schuchardt D., Vergara J.M., Fernández-Palacios H., Kalinowski C.T., Hernández-Cruz C.M., Izquierdo M.S. \& Robaina L. (2007) Effects of dietary protein and lipid levels on growth feed utilization and body composition of red porgy (Pagrus pagrus) fingerlings. Aquaculture Nutrition 13, 1-9.

Shimada K., SakumaY.,Wakamatsu J., Fukushima M., Sekikawa M., Kushida K. \& Mikami M. (2004) Species and muscle differences in L-carnitine levels in skeletal muscles based on a new simple assay. Meat Science 68, 357-362.

Tejera N., Cejas J.R., Rodriguez C., Bjerkeng B., Jerez S., Bolanos A. \& Lorenzo A. (2007) Pigmentation, carotenoids, lipid peroxides and lipid composition of skin of red porgy (Pagrus pagrus) fed diets supplemented with different astaxanthin sources. Aquaculture 270, 218-230.

Wang Y., Cui Y.,Yang Y. \& Cal F. (2000) Compensatory growth in hybrid tilapia, Oreochromis mossambicus $\times$ O. niloticus reared in seawater. Aquaculture 189, 101-108.

Wassef E.A.,Wahby O.M. \& Sakr E.M. (2007) Effect of dietary vegetable oils on health and liver histology of gilthead seabream (Sparus aurata) growers. Aquaculture Research 38, 852-861.

Weatherley A.H. \& Gill H.S. (1981) Recovery growth following periods of restricted rations and starvation in 
Rainbow trout, Salmo gardneri Richardson. Journal Fish Biology 18, 195-208.

Weatherley A.H. \& Gill H.S. (1987) The Biology of Fish Growth. Academic press, London, UK, 443pp.

Webster C.D.,Tidwell J.H., Goodgame L.S. \& Yancey D.H. (2007) Effects of fasting on fatty acid composition of muscle, liver and abdominal fat in channel catfish Ictalurus punctatus. Journal of the World Aquaculture Society 25, 126-134.

Yang S.D., Wen Y.C., Liou C.H. \& Liu F.G. (2009) Influence of dietary L-carnitine on growth, biological traits and meat quality in Tilapia. Aquaculture Research 40, 1374-1382. 